\title{
Characterization of exceptionally thermostable single-stranded DNA-binding proteins from Thermotoga maritima and Thermotoga neapolitana
}

\author{
Marcin Olszewski ${ }^{1 *}$, Anna Grot ${ }^{1}$, Marek Wojciechowski ${ }^{2}$, Marta Nowak', Małgorzata Mickiewicz ${ }^{1}$, Józef Kur ${ }^{1}$
}

\begin{abstract}
Background: In recent years, there has been an increasing interest in SSBs because they find numerous applications in diverse molecular biology and analytical methods.

Results: We report the characterization of single-stranded DNA binding proteins (SSBs) from the thermophilic bacteria Thermotoga maritima (TmaSSB) and Thermotoga neapolitana (TneSSB). They are the smallest known bacterial SSB proteins, consisting of 141 and 142 amino acid residues with a calculated molecular mass of 16.30 and $16.58 \mathrm{kDa}$, respectively. The similarity between amino acid sequences of these proteins is very high: $90 \%$ identity and 95\% similarity. Surprisingly, both TmaSSB and TneSSB possess a quite low sequence similarity to Escherichia coli SSB (36 and 35\% identity, 55 and 56\% similarity, respectively). They are functional as homotetramers containing one single-stranded DNA binding domain (OB-fold) in each monomer. Agarose mobility assays indicated that the ssDNA-binding site for both proteins is salt independent, and fluorescence spectroscopy resulted in a size of $68 \pm 2$ nucleotides. The half-lives of TmaSSB and TneSSB were $10 \mathrm{~h}$ and $12 \mathrm{~h}$ at $100^{\circ} \mathrm{C}$, respectively. When analysed by differential scanning microcalorimetry (DSC) the melting temperature $\left(T_{\mathrm{m}}\right)$ was $109.3^{\circ} \mathrm{C}$ and $112.5^{\circ} \mathrm{C}$ for TmaSSB and TneSSB, respectively.

Conclusion: The results showed that TmaSSB and TneSSB are the most thermostable SSB proteins identified to date, offering an attractive alternative to TaqSSB and TthSSB in molecular biology applications, especially with using high temperature e. g. polymerase chain reaction (PCR).
\end{abstract}

\section{Background}

Single-stranded DNA-binding (SSB) proteins play an essential role in all in vivo processes involving ssDNA. They interact with ssDNA and RNA, in an independent from sequence manner, preventing single-stranded nucleic acids from hybridization and degradation by nucleases [1]. SSB proteins play a central role in DNA replication, repair and recombination [2-4]. They have been identified in all classes of organisms, performing similar functions but displaying little sequence similarity and very different ssDNA binding properties. Based on their oligomeric state, SSBs can be classified into four groups: monomeric, homodimeric, heterotrimeric and homotetrameric. A prominent feature of all SSBs is that

\footnotetext{
* Correspondence: molszewski@pg.gda.pl

'Gdańsk University of Technology, Department of Microbiology, ul.

Narutowicza 11/12, 80-233 Gdańsk, Poland

Full list of author information is available at the end of the article
}

the DNA-binding domain is made up of a conserved motif, the OB (oligonucleotide binding) fold [5]. Most of the bacterial SSBs exist as homotetramers. However, recent discoveries have shown that SSB proteins from the genera Thermus and Deinococcus possess a different architecture. SSB proteins in these bacteria are homodimeric, with each SSB monomer encoding two OB folds linked by a conserved spacer sequence [6-9].

At present, with the exception of SSB from Thermoanaerobacter tengcongensis [11], all bacterial thermostable SSBs belong to the Deinococcus-Thermus phylum. They have been found in T. aquaticus [6,12], T. thermophilus [6,12], D. radiodurans [7], D. geothermalis [13], D. murrayi [14], D. radiopugnans [15], D. grandis and D. proteolyticus [16]. In addition, thermostable SSBs have also been found in thermophilic crenarchaea e. g. Sulfolobus solfataricus [17]. 
Thermotoga maritima and T. neapolitana are strictly anaerobic heterotrophic Eubacteria growing in marine environments at temperatures ranging from 50 to $95^{\circ} \mathrm{C}$. Their DNA base composition is 46 and $41 \mathrm{~mol} \%$ guanine+cytosine, respectively $[18,19]$. Among the Eubacteria sequenced to date, T. maritima has the highest percentage (24\%) of genes that are highly similar to archeal genes. The observed conservation of gene order between T. maritima and Archaea in many of the clustered regions suggests that lateral gene transfer may have occurred between thermophilic Eubacteria and Archaea [20].

Genomes of bacteria presented in the NCBI database have been screened in search for $s s b$ gene homologs and their organization. In all the genomes, one or more genes coding for an SSB homolog were found [21]. On the basis of the $s s b$ gene organization and the number of $s s b$ paralogs, they classified bacteria in four different groups. T. maritima was classified as group II, which contains bacteria with the $s s b$ gene organization rpsFssb-rpsR.

In the present study the purification and characterization of two highly thermostable SSB proteins from T. maritima and T. neapolitana are described.

\section{Results}

\section{Sequence analysis}

The TmaSSB and TneSSB proteins contained 141 and 142 amino acid residues with a calculated molecular mass of 16.30 and $16.58 \mathrm{kDa}$, respectively. They are the smallest prokaryotic SSB proteins so far identified (E. coli SSB with N-terminal methionine consists of 178 amino acid residues). Analysis of the primary structures by RPS-BLAST [22] revealed the presence of two distinctive regions: one putative $\mathrm{OB}$-fold domain (from amino acid 1-120) and one C-terminal domain that contains five conserved DEPPF terminal amino acids, which are common in all known bacterial SSB proteins.

Figure 1 shows an alignment of amino acid sequences of T. maritima, T. neapolitana, Thermoanaerobacter tengcongensis, Sulfolobus solfataricus and E. coli SSB proteins containing one OB-fold domain for monomer, and $T$. aquaticus, T. thermophilus, D. geothermalis and $D$. radiopugnans thermostable $\mathrm{SSB}$ proteins containing two OB-fold domains for monomer. The similarity between the amino acid sequences of Thermotoga SSBs is very high: $90 \%$ identity and $95 \%$ similarity. Surprisingly, both Thermotoga SSBs had a quite low sequence similarity to Escherichia coli SSB (TmaSSB has 36\% identity and 55\% similarity, TneSSB has $35 \%$ identity and $56 \%$ similarity), whereas the similarity to Thermoanaerobacter tengcongensis SSB3 was higher (63 and 64\% similarity; 40 and $42 \%$ identity for TmaSSB and TneSSB, respectively).

\section{Expression and purification of the recombinant TmaSSB and TneSSB proteins}

Using the recombinant plasmid pETSSBTma or pETSSBTne, the expression of inducible proteins with the predicted size was excellent (Figure 2, lanes 1 and 5). Both proteins were expressed in a soluble form in the cytosol. Heat treatment resulted in considerably less contamination by the host proteins (Figure 2, lanes 2 and 6). The $E$. coli overexpression system used in this study produced about 40 and $35 \mathrm{mg}$ of purified TmaSSB and TneSSB protein, respectively, from 11 of induced culture. The purity of the protein preparations was about $99 \%$ (Figure 2, lanes 4 and 8).

\section{Oligomerization status of the TmaSSB and TneSSB proteins}

Analysis of the purified proteins by SDS-PAGE revealed a single major band with a molecular mass of about $16 \mathrm{kDa}$ for both proteins. In contrast, analysis by gel filtration chromatography revealed single peaks with a molecular mass of about $60.48 \mathrm{kDa}$ for TmaSSB and $61.86 \mathrm{kDa}$ for TheSSB (Figure 3). This native molecular mass is approximately is 3.7 times the molecular mass of the monomer for both proteins. This confirmed our prediction that in solution the TmaSSB and TneSSB proteins exist as homotetramers. Chemical cross-linking using glutaraldehyde confirmed the tetrameric state of the examined proteins (not shown).

\section{DNA-binding properties}

When $(\mathrm{dT})_{35},(\mathrm{dT})_{60}$ or $(\mathrm{dT})_{76}$ were incubated with increasing amounts of TmaSSB or TheSSB, a single band of reduced mobility was observed (Figure 4, complex I). Most of those oligonucleotides were shifted after addition of 10 pmol of SSBs, and the mobility of the shifted band remained constant at the higher protein amounts (100 pmol). One band of identical mobility was observed for $(\mathrm{dT})_{120}$ at the low protein amounts, but a second band with a lower mobility appeared at the higher protein amounts (100 pmol; Figure 4, complex II)). These results suggest that TmaSSB and TneSSB bind to $(\mathrm{dT})_{35},(\mathrm{dT})_{60}$ or $(\mathrm{dT})_{76}$ as one single homotetramer whereas two SSB homotetramers bind to $(\mathrm{dT})_{120}$. Similar binding patterns were observed with the TmaSSB and TneSSB proteins in different salt concentrations ( 2 or $100 \mathrm{mM} \mathrm{NaCl}$ ).

The binding of the TmaSSB and TneSSB proteins to the naturally occurring circular M13 ssDNA $(6,407$ nucleotides) was also examined. In this experiment, a fixed amount of M13 ssDNA was incubated with increasing amounts of SSB protein, and the resulting complexes were analyzed by agarose gel electrophoresis (Figure 4). When increasing amounts of TmaSSB or TneSSB protein were added to M13 ssDNA, there was a progressive decrease in the mobility of the M13 ssDNA. 


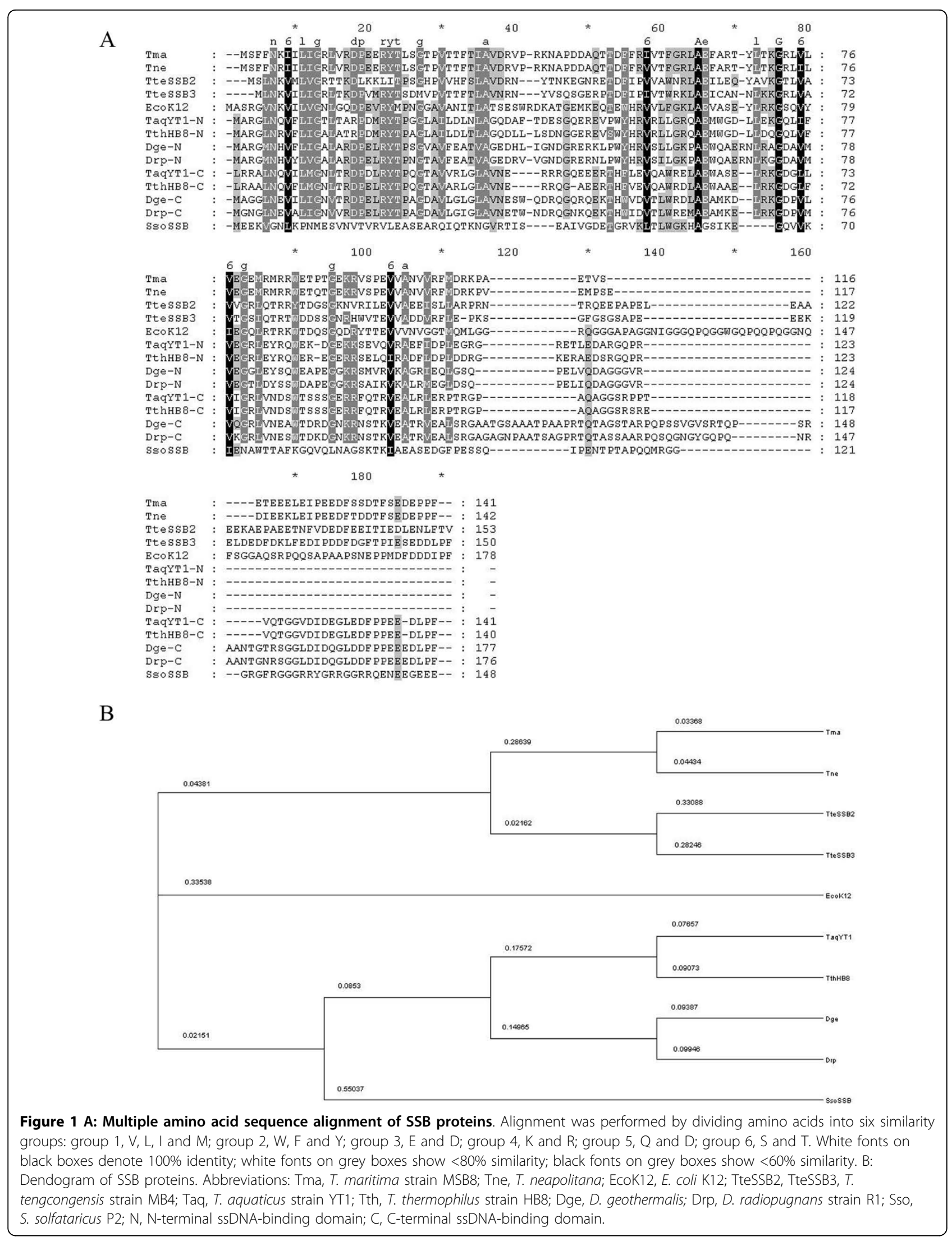




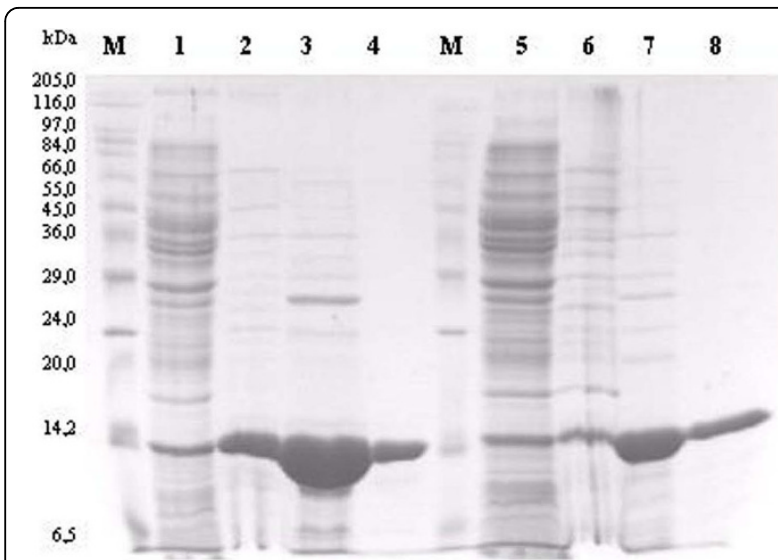

Figure 2 Expression and purification of the TmaSSB and TneSSB. Proteins expression were obtained from the pET30Ek/LIC vector in BL(DE3)pLysS E. coli cells. Proteins were examined on 15\% SDS-polyacrylamide gel. Lane M, Marker Wide Range (Sigma) with the molecular mass of proteins marked; lanes 1 and 5, soluble protein cell extracts after IPTG induction of protein expression (10 $\mathrm{\mu l}$ ); lanes 2 and $6, \operatorname{TmaSSB}$ and TneSSB after heat treatment at $80^{\circ} \mathrm{C}$ for $20 \mathrm{~min}(10 \mu \mathrm{l})$; lane 3 and 7, TmaSSB and TheSSB after chromatography on a QAE-cellulose column $(10 \mu \mathrm{l})$; lane 4 and 8, TmaSSB and TneSSB after chromatography on a ssDNA-cellulose column $(10 \mu l)$.

To further explore the binding properties of the examined SSB proteins, we used fluorescence spectroscopy. All bacterium SSB proteins (both homotetrameric and homodimeric) studied so far have shown a dramatic decrease of tryptophan fluorescence when binding to ssDNA. With an excitation wavelength of $295 \mathrm{~nm}$, the emission spectrum of SSB proteins at $25^{\circ} \mathrm{C}$ had a maximum at $348 \mathrm{~nm}$, which is consistent with tryptophan fluorescence. When adding a saturating quantity of ssDNA, the intrinsic fluorescence at $348 \mathrm{~nm}$ was

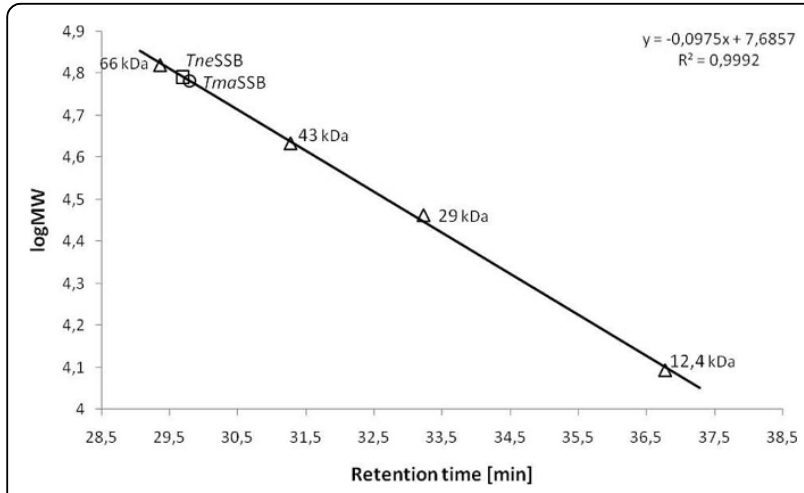

Figure 3 Analytical gel filtration of TmaSSB and TneSSB on Superdex HR 75 column. A standard linear regression curve was generated by plotting the log of the molecular mass of the calibration proteins against their retention times (min) and is shown. The calibration proteins include bovine albumin ( $66 \mathrm{kDa})$, ovalbumin (43 kDa), carbon anhydrase (29 kDa) and cytochrome C (12.4 kDa). quenched by $95 \%$ for both the TmaSSB and the TneSSB proteins. The estimated size of the ssDNA binding site in the presence of 2 or $100 \mathrm{mM}$ of $\mathrm{NaCl}$ for the TmaSSB and the TneSSB proteins was $68 \pm 2$ nt (Figure $5)$. None binding-mode transition was observed when changing the ionic strength from low $(2 \mathrm{mM} \mathrm{NaCl})$ to high salt $(100 \mathrm{mM} \mathrm{NaCl})$. In all cases, the cooperative affinity is estimated to be in the range of $10^{7}-10^{8} \mathrm{M}^{-1}$.

\section{Thermostability}

The half-lives of the ssDNA-binding activities of TmaSSB and TneSSB at $100^{\circ} \mathrm{C}$, determined by gel mobility shift assays, were $10 \mathrm{~h}$ and $12 \mathrm{~h}$, respectively. The thermostability for $\mathrm{TaqSSB}$ was $30 \mathrm{~s}$ at $95^{\circ} \mathrm{C}, 3 \mathrm{~min}$ at $90^{\circ} \mathrm{C}$ and $15 \mathrm{~min}$ at $85^{\circ} \mathrm{C}$, as was also shown by Dąbrowski et al. [6].

When analyzed by differential scanning microcalorimetry (DSC) the thermal unfolding of TmaSSB, TneSSB and TaqSSB was found to be an irreversible process, as seen in the rescan thermograms (Figure 6). The TneSSB had the highest thermostability, with a melting temperature $\left(T_{\mathrm{m}}\right)$ of $112,5^{\circ} \mathrm{C}$, whereas $T m a S S B$ had a $T \mathrm{~m}$ of $109,3^{\circ} \mathrm{C}$ (Figure 6 ). The melting temperature of TaqSSB was only $86,8^{\circ} \mathrm{C}$. This difference in $T_{\mathrm{m}}$ confirmed the different thermostabilities of the proteins indicated by the observed half-lives of the ssDNA binding activities. The thermograms of these SSB proteins did not show any characteristic signs of heavily aggregated proteins after heat denaturation. Moreover, the results of the DSC and the half-lives of the ssDNA binding activities suggest that the loss of binding activity of TmaSSB, TneSSB and TaqSSB was connected with an irreversible thermal unfolding of the proteins.

In summary, the results showed that TmaSSB and TneSSB are the most thermostable SSB proteins identified to date.

\section{Discussion}

In this study, we have described the purification and characterization of SSB proteins from the thermophilic bacteria $T$. maritima and $T$. neapolitana. The results of the sequence analysis verified that a ssDNA binding domain (the first 106 amino acid residues) in one monomer of both TmaSSB and TneSSB proteins possess a canonical oligonucleotide binding fold (OBfold), very similar to the observed in the structure of E. coli SSB [23,24]. Both TmaSSB and TneSSB form tetramers in solution as was shown by the gel filtration chromatography experiments. Furthermore, they possess the shortest and most acidic C-terminal domains yet identified (from 107 to 141 or 142 amino acid residues, respectively). The $\mathrm{C}$-terminal domains contain $40 \%$ and $41.7 \%$ negatively charged amino acids, respectively. 


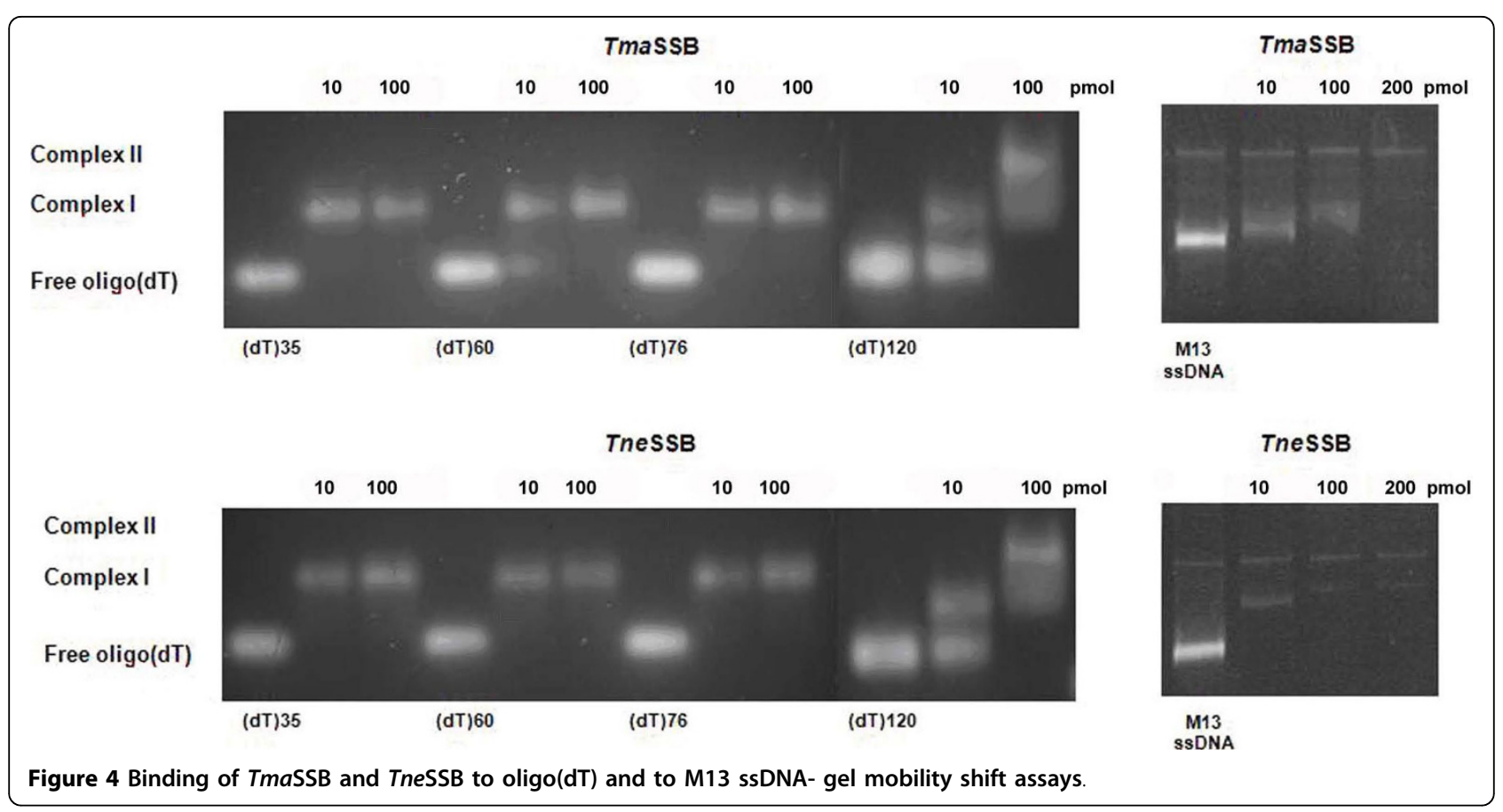

Studies of other SSBs have often shown that the size of the binding site depends on the salt concentration. For example, for $E \operatorname{coSSB}$, at least two distinctly different DNA-binding modes have been described [3]. In high salt concentrations, $65 \mathrm{nt}$ bind per EcoSSB tetramer with almost $90 \%$ fluorescence quench, whereas in low salt concentrations $35 \mathrm{nt}$ are sufficient to saturate the protein and quench its fluorescence by only $53 \%$. This phenomenon has also been demonstrated for all known Deinococcus-Thermus SSBs [6,13-16]. However, such a distinctly different binding mode in high salt concentrations was not observed for the TmaSSB and TneSSB proteins. The agarose gel mobility assays indicated that the binding site per tetramer is salt independent and is approximately 68 nucleotides based on fluorescence spectroscopy.

TmaSSB and TneSSB proteins originating from the same genus, Thermotoga, showed quite similar thermostability (measured with an indirect method), i.e. $10 \mathrm{~h}$ and $12 \mathrm{~h}$ at $100^{\circ} \mathrm{C}$, respectively. Both proteins possessed a higher thermostability than even the most thermostable TteSSB2, which maintained full activity even after $6 \mathrm{~h}$ of incubation at $100^{\circ} \mathrm{C}$ [11]. Additionally, the results of differential scanning microcalorimetry (DSC) also demonstrated a very high thermostability of both the SSB proteins. TneSSB had a higher thermostability $\left(T_{\mathrm{m}}\right.$ of $112,5^{\circ} \mathrm{C}$ ) than $\operatorname{TmaSSB}\left(\operatorname{Tm}\right.$ of $\left.109,3^{\circ} \mathrm{C}\right)$, whereas in comparison the melting temperature of TaqSSB was only $86,8^{\circ} \mathrm{C}$. Therefore the thermostability of TmaSSB or TneSSB was much higher in comparison to the thermostability of homodimeric SSBs from the thermophilic T. aquaticus, D. radiopugnans [15] and D. murrayi [14].
In conclusion, the TmaSSB and TneSSB are the most thermostable SSB protein identified up to date, offering an attractive alternative for TaqSSB and TthSSB for applications in molecular biology and for analytical purposes especially for PCR and RT-PCR.

None of the two SSB proteins from Thermotoga seemed to possess any special features relative to EcoSSB and compared with other known thermostable SSBs. Neither their relative content of different amino acids nor the sequence comparisons could fully explain the cause of their exceptional thermostability. However, there were certain differences in the content of some amino acid residues. For example, the space between the highly hydrophobic core monomer and the highly acidic C-terminal fragment is very short in the TmaSSB and TneSSB proteins in comparison with EcoSSB. This has also been demonstrated for SSBs from other highly thermophilic microorganisms like T. aquaticus and T. thermophilus [6]. This characteristically short and flexible C-terminus could protect the protein from thermal denaturation and make it more thermostable [6].

Based on the structure data the TmaSSB and EcoSSB proteins (without their flexible C-termini) [30,24] were analyzed to find more clues about the thermostability of SSBs from Thermotoga. The homology modeling of the protein regions which lack electron density was carried out using Modeller version 9.2 [31]. The modeled residues were 24 and 25, 38 to 48, 86 to 92 of TmaSSB and 1 and 2, 24 to 27, 40 to 49 of EcoSSB.

Thermostability seems to be a property acquired by a protein through a combination of many small structural 


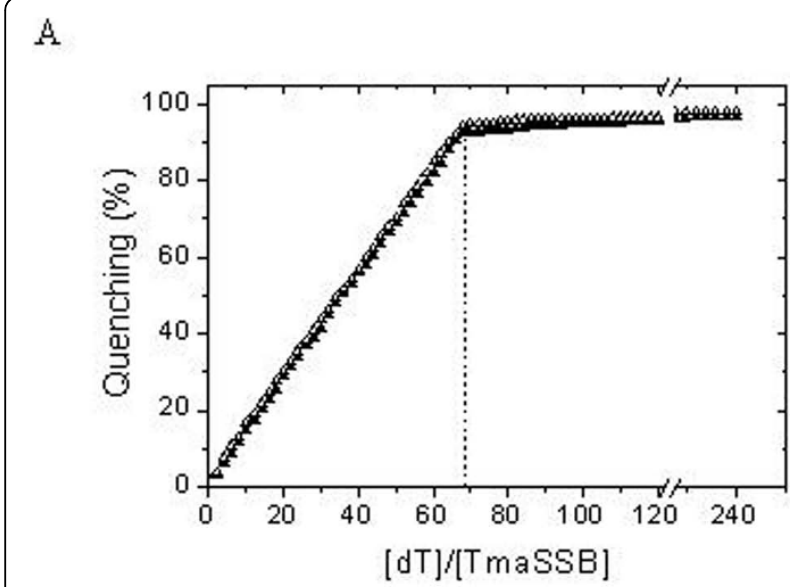

B

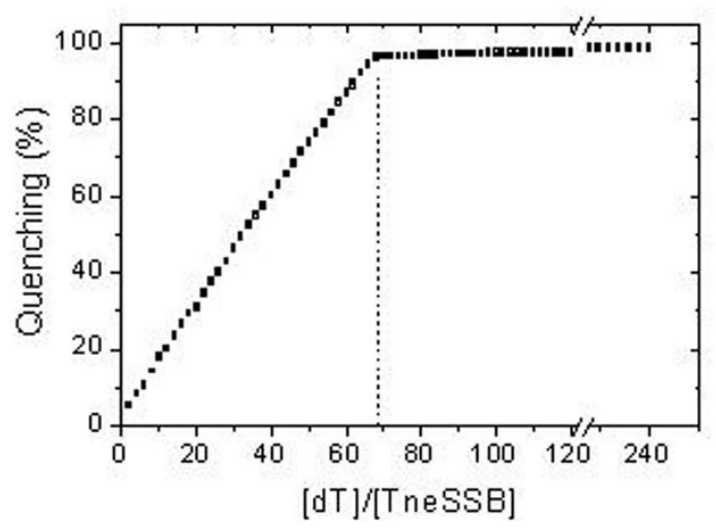

Figure 5 Inverse fluorescence titration of TmaSSB and TneSSB with (dT) $)_{\mathbf{7 6}}$. A $1 \mathrm{nM}$ sample of TmaSSB (A) and TneSSB (B) was titrated with (dT) 76 at $2 \mathrm{mM} \mathrm{NaCl}$ (filled figures) or $100 \mathrm{mM} \mathrm{NaCl}$ (open figures) in binding buffer.

modifications that are achieved with the exchange of some amino acid residues for others and the modulation of the canonical forces (e.g. hydrogen bonds, disulfide bonds, ion-pair interactions, hydrophobic interactions) found in all proteins [32]. The molecular mechanisms of thermostability are varied and depend on the specific protein [33]. The factors contributing to the protein stability include additional intermolecular interactions (e.g. hydrogen bonds, disulfide bonds, ion-pair interactions, hydrophobic interactions) and good general conformation structure (i.e. compact packing, more rigid, conformational strain release) [32].

The structural similarity between the TmaSSB and EcoSSB proteins is quite high but there are many characteristic features in the structures of TmaSSB monomer and tetramer which account for the thermostability [Tab. 1]. The amount of salt bridges in thermophile proteins is higher than in the equivalent proteins of mesophiles. The number of salt bridges in the tetramer of TmaSSB is by over $50 \%$ higher than in the EcoSSB

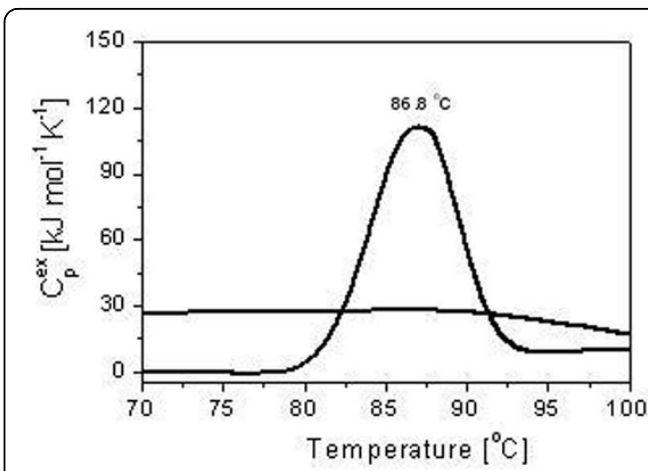

TaqSSB

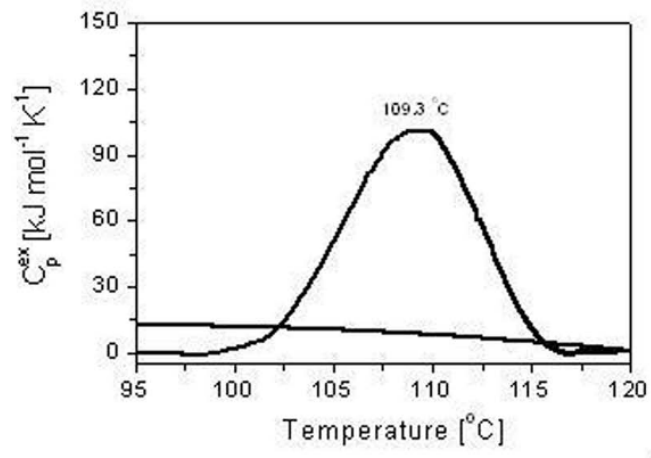

TmaSSB

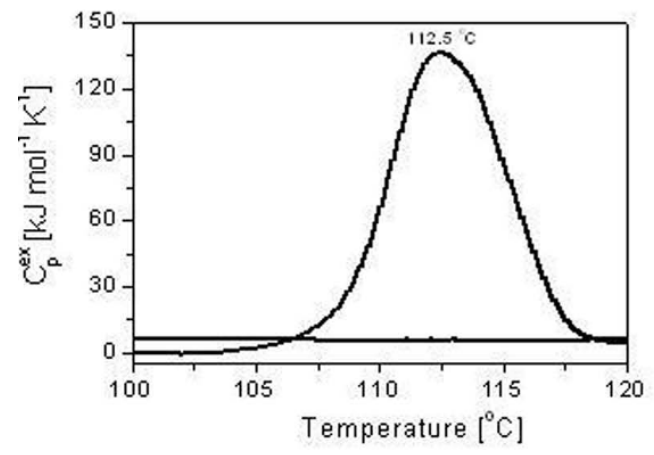

TneSSB

Figure 6 DSC thermograms of SSB proteins. Samples containing $1.5 \mathrm{mg} / \mathrm{ml} \mathrm{SSB}$ were analyzed in $50 \mathrm{mM}$ potassium phosphate buffer $\mathrm{pH} 7.5$ and $0.1 \mathrm{M} \mathrm{NaCl}$.

tetramer, whereas in the TmaSSB monomer it is even by $100 \%$ higher than in the EcoSSB. A few of the TmaSSB salt bridges are particularly important for the protein stability, e.g. one of them which stabilizes the C-terminus (Figure 7A). It was showed that protein thermostability is correlated with the number of hydrogen bonds. The terminal $\beta$-strand ( $\beta 6$ ) of TmaSSB is a single long strand stabilized by the hydrogen bonds with the residues of the preceding antiparallel $\beta$-strand ( $\beta 5)$, whereas in EcoSSB there are two shorter $\beta$-strands $\left(\beta 45_{2}\right.$ and $\beta 5$ ) divided by an additional loop that destabilizes this important region (Figure 7B). These two 
Table 1 Results of structural comparison TmaSSB and EcoSSB proteins. Packing density calculated by means Voronoia software and procedure described in [38]

\begin{tabular}{|c|c|c|c|c|c|c|}
\hline & \multirow[t]{2}{*}{ Packing Density } & \multirow[t]{2}{*}{ Cavities } & \multicolumn{2}{|c|}{ Amino acid residues } & \multicolumn{2}{|c|}{ Shape correlation statistic (Sc) } \\
\hline & & & Pro & Gly & $(\mathrm{A} / \mathrm{B})$ & $(A B / C D)$ \\
\hline Monomer EcoSSB & 0.73 & 1 & 2 & 12 & 0.68 & 0.56 \\
\hline Tetramer EcoSSB & 0.71 & 16 & 8 & 48 & & \\
\hline Monomer TmaSSB & 0.74 & 1 & 6 & 6 & 0.77 & 0.74 \\
\hline Tetramer TmaSSB & 0.72 & 12 & 24 & 24 & & \\
\hline
\end{tabular}

intermolecular interactions, stabilize this essential protein region thus enhancing the anchoring the TmaSSB $\mathrm{C}$-terminus. The amino acid sequence alignments of thermophilic and the mesophilic proteins have displayed some significant substitutions in thermophilic proteins such as Gly to Pro [34]. The OB-fold of TmaSSB protein has a threefold higher content of Pro residues, whereas the content of Gly residues is twice lower than that of EcoSSB [Tab. 1]. Furthermore, there are three loops containing Pro residues in the TmaSSB protein and there is only one in EcoSSB, which makes the former less susceptible to unfolding than the latter.

Enhanced molecular compactness can enhance thermal stability. Compactness can be achieved by e.g. optimized packing or the elimination of unnecessary cavities [35]. The packing density of both a monomer and tetramer is slightly higher in TmaSSB whereas the number of cavities is as much as 25\% higher in EcoSSB.

In order to examine the geometrical fit between the surfaces $A$ and $B$ subunits and $A B$ and $C D$ pairs of SSB proteins $[30,24]$, the shape correlation statistic (Sc) [36] for TmaSSB and EcoSSB interfaces were calculated. This statistic provides a measure of packing of two protein surfaces. A value of $\mathrm{Sc}=0$ indicates no geometrical fit, whereas a value of $\mathrm{Sc}=1$ corresponds to two perfectly packed surfaces. Calculation of the shape correlation

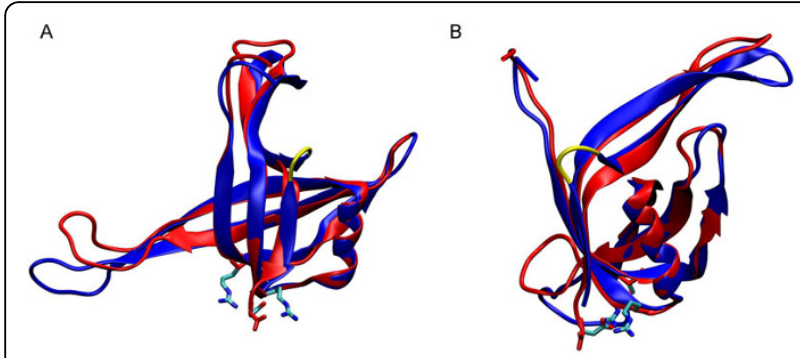

Figure 7 Structural superposition of the DNA-binding domain of the TmaSSB and EcoSSB. Two views of superposition of TmaSSB (red) and ECOSSB (blue) rotated against each others to visualized salt bridge and flexible loop. The superposition indicates a structurally conserved core with flexible loops. (A) The discussed salt bridge TmaSSB protein between Asp108 (red) and Arg12 (light blue) and Arg73 (light blue). (B) The additional flexible loop of EcoSSB (yellow). Structures prepared with using VMD version 1.8.7 [37]. statistic gave a value of $\mathrm{Sc}=0.68$ or 0.77 for the interface of monomers A/B EcoSSB and TmaSSB, respectively. But surprisingly even more difference was for this parameter for interfaces between paired monomers $\mathrm{AB} /$ CD that equals 0.56 and 0.74 for EcoSSB and TmaSSB, respectively. These results indicate specifically that geometrical fit between TmaSSB protein surfaces is incomparably higher than EcoSSB.

In $E$. coli, the SSB base-stacking residues are Trp-40, Trp-54, Phe-60, and Trp-88, and in both TmaSSB and TneSSB the related residues are Phe-31, Phe-52 or Phe53 , Phe-58 or Phe-64 and Trp-86 (Figure 1). Highly conserved His-55, Gln-76 and Gln-110, important for homotetramerization of EcoSSB, were not found in the SSB proteins from Thermotoga.

\section{Conclusions}

We report here the purification and characterization of T. maritima and T. neapolitana SSBs, and how they relate to, and differ from, other members of this important class of proteins.

The TmaSSB and TneSSB are the smallest known bacterial SSB proteins, their molecular mass deduced from the 141 and 142 amino acid sequences were 16.30 and $16.58 \mathrm{kDa}$, respectively.

The half-lives of TmaSSB and TneSSB were extremely long: $10 \mathrm{~h}$ and $12 \mathrm{~h}$ at $100^{\circ} \mathrm{C}$, respectively. When analyzed by differential scanning microcalorimetry (DSC) the melting temperature $\left(T_{\mathrm{m}}\right)$ was $109.3^{\circ} \mathrm{C}$ and $112.5^{\circ} \mathrm{C}$ for TmaSSB and TneSSB, respectively. These results were very surprising in the context of half-life of SSB proteins from thermophilic Thermus and Deinococcus.

The results showed that TmaSSB and TneSSB are the most thermostable SSB proteins identified to date and those thermostability of both SSB proteins offer an attractive tool for many applications in molecular techniques, especially for thermal nucleic acids amplification methods (e. g. PCR)

\section{Methods}

Bacterial strains, plasmids, enzymes and reagents

Thermotoga maritima MSB8 (DSM 3106) and T. neapolitana (DSM 4359) were purchased from DSMZ (Deutsche Sammlung von Mikroorganismen und 
Zellkulturen GmbH, Germany). The E. coli TOP10F' (Invitrogen, USA) and BL21(DE3)pLysS (Novagen, UK) strains were used for genetic constructions and proteins expression, respectively. The reagents for PCR, the oligodeoxynucleotides, and the oligonucleotides 5 '-endlabelled with fluorescein were purchased from DNAGdańsk II (Poland). Restriction enzymes, IPTG, and agarose were from Fermentas (Lithuania). The plasmid pET30Ek/LIC (Novagen, UK) was used for construction of the expression system. The reagents for protein purification were purchased from Sigma-Aldrich (USA).

\section{Cloning the ssb genes from T. maritima and $\mathrm{T}$. neapolitana}

Chromosomal DNA from T. maritima and T. neapolitana was isolated using the Genomic DNA AX Bacteria kit (A\&A Biotechnology, Poland). In the T. maritima (GenBank accession no. AE000512) genome, the $s s b$ gene is flanked by the conservative $r p s F$ and $r p s R$ genes encoding the ribosomal proteins S6 and S18. Hence, primers complementary to the most conservative regions of those genes were designed and synthesized for PCR amplification. The forward primer was 5'-GGGTATGAGAAAGTTCGCCT (20 nt) and the reverse primer was 5' ATCTGTCTTGCCCTTTTGATG (21 nt). PCR reactions were performed using $1 \mathrm{U}$ of $P$ wo polymerase (DNA-Gdańsk II, Poland) in $50 \mu \mathrm{l}$ buffer containing $10 \mathrm{mM} \mathrm{KCl}, 20 \mathrm{mM}$ Tris- $\mathrm{HCl} \mathrm{pH} 8.8,10 \mathrm{mM}(\mathrm{NH})$ ${ }_{2} \mathrm{SO}_{4}, 0.1 \%$ Triton X-100, $2 \mathrm{mM} \mathrm{MgSO}, 1 \mathrm{mM}$ dNTPs, $0.4 \mu \mathrm{M}$ of each primer and approximately $200 \mathrm{ng}$ of T. maritima or T. neapolitana DNA. Forty cycles were performed with a temperature profile of $60 \mathrm{~s}$ at $94^{\circ} \mathrm{C}$, $90 \mathrm{~s}$ at $54^{\circ} \mathrm{C}$ and $120 \mathrm{~s}$ at $72^{\circ} \mathrm{C}$. Specific PCR products, about $900 \mathrm{bp}$, were obtained and sequenced to confirm the presence of $s s b$-like gene.

Based on the $s s b$ gene sequences from $T$. maritima and T. neapolitana, gene-specific primers for PCR were designed and synthesized. PCR was carried out using the forward 5'-GCGCATATGTCTTTCTTCAACAAGATC (27 nt) and reverse 5'-ATAAGCTTAATCAAAATG GTGGTTCATC (28 nt) primers for the $s s b$ gene of $T$. maritima and the forward 5'- GCGCATATGTCTTTTTTCAACAGGATC (27 nt) and reverse 5'-ATAAGCTTAATCAGAATGGCG GTTCGTC (28 nt) primers for the $s s b$ gene of $T$. neapolitana. The boldface parts of the primer sequences are complementary to the nucleotide sequences of the $s s b$ genes in $T$. maritima and $T$. neapolitana, respectively, whereas the 5 ' overhanging ends of the primers contain recognition sites for restriction endonucleases and are designed to facilitate cloning (the NdeI and HindIII recognition sites are underlined; the ATG start codon and TGA stop codon are shown in italics). The PCR conditions were the same as described above. Both PCR products
$(0.5 \mu \mathrm{g})$ were digested with $\mathrm{NdeI}$ and HindIII and analyzed by electrophoresis on a $1 \%$ agarose gel stained with ethidium bromide. Specifically, approximately 420 bp amplification products were cut out of the gel and purified using the Gel-Out AX kit (A\&A Biotechnology, Poland). The purified DNA fragments were ligated into pET30Ek/LIC between the NdeI and HindIII sites. E. coli strains TOP10F' cells were transformed with the ligation mixtures and the colonies obtained were examined for the presence of $s s b$ genes from $T$. maritima and T. neapolitana by PCR amplification and restriction analysis. Single clones, named pETSSBTma and pETSSBTne, were selected and sequenced to ascertain the authenticity of the clones. The constructed plasmids were used in the expression and purification procedure described below.

\section{Protein sequence analysis of the TmaSSB and TneSSB}

The amino acid sequences of the TmaSSB and TneSSB proteins were analyzed using standard protein-protein BLAST and RPS-BLAST. Multiple sequence alignments were created using the program MAFFT and the results were analyzed and edited using the editor program GeneDoc (copyright by Karl Nicholas). Dendogram of the amino acid sequences of SSB proteins were edited using the editor program Dendroscope [25].

\section{Expression and purification of the TmaSSB and TneSSB}

The E. coli BL21(DE3)pLysS strain transformed with pETSSBTma or pETSSBTne was grown at $37^{\circ} \mathrm{C}$ in $0.5 \mathrm{~L}$ LB containing $34 \mu \mathrm{g} / \mathrm{ml}$ kanamycin and $50 \mu \mathrm{g} / \mathrm{ml}$ chloramphenicol to an $\mathrm{OD}_{600}$ of 0.4 . Expression was then induced by addition of IPTG to a final concentration of $0.5 \mathrm{mM}$. After $6 \mathrm{~h}$, the cells were harvested by centrifugation, and suspended in $50 \mathrm{ml}$ buffer A (20 mM Tris$\mathrm{HCl} \mathrm{pH} 8.0,50 \mathrm{mM} \mathrm{NaCl}, 1 \mathrm{mM}$ EDTA, 0.1\% Triton $\mathrm{X}-100)$. The purification procedure was very similar to the previously published purification scheme for the SSB from calf thymus [26], and that for thermostable SSB proteins [6]. Generally, the cells were disrupted by sonication and the insoluble debris were removed by centrifugation. The supernatant was heat-treated at $80^{\circ} \mathrm{C}$ for $20 \mathrm{~min}$ and denatured mesophilic proteins were discarded by centrifugation. This supernatant was directly loaded on a QAE-cellulose column (50 ml bed volume, Sigma-Aldrich, USA), from which the proteins were eluted with a linear gradient of $0.05-2 \mathrm{M} \mathrm{NaCl}$ in buffer B (20 mM Tris- $\mathrm{HCl} \mathrm{pH} 8.0,50 \mathrm{mM} \mathrm{NaCl}, 1 \mathrm{mM}$ EDTA). The SSB-containing fractions, detected by SDSPAGE, were combined and loaded on a ssDNA-cellulose column ( $5 \mathrm{ml}$, USB, USA). SSB proteins were eluted with gradient of $0.5-1.5 \mathrm{M} \mathrm{NaCl}$ and $50 \%$ ethylene glycol. The fractions with SSB proteins were collected and dialyzed against buffer B, concentrated using an Amicon 
Ultra-10 centrifugal filter device (Millipore, USA), and stored at $-20^{\circ} \mathrm{C}$ in buffer $\mathrm{C}(20 \mathrm{mM}$ Tris- $\mathrm{HCl} \mathrm{pH}$ 8.0, 50 $\mathrm{mM} \mathrm{NaCl}, 1 \mathrm{mM}$ EDTA, 50\% glycerol, 0.05\% Igepal) until used. The purity of TmaSSB and TneSSB proteins was examined by the optical densitometry on the SDSPAGE gel and the amounts were estimated spectrophotometrically using the appropriate absorption coefficient factor.

\section{Estimation of the native molecular mass}

The molecular mass of the TmaSSB and the TneSSB protein was determined by two independent methods: (i) FPLC gel filtration on a Superdex HR 75 column (Amersham Bioscience AB, Sweden), (ii) optimized chemical cross-linking experiments using $0.1 \%(\mathrm{v} / \mathrm{v})$ glutaraldehyde for 1-30 min with TmaSSB or TneSSB concentrations between 50 and $500 \mu \mathrm{g} / \mathrm{ml}$ [27]. Bovine albumin (66 $\mathrm{kDa})$, ovalbumin $(43 \mathrm{kDa})$, carbon anhydrase $(29 \mathrm{kDa})$ and cytochrome $\mathrm{C}(12.4 \mathrm{kDa})$ were used as standard proteins for calibration in the gel filtration assay.

\section{Gel mobility shift assays: binding to ss oligonucleotides}

A fixed quantity $(10 \mathrm{pmol})$ of 5 '-end fluorescein-labelled oligonucleotides $(\mathrm{dT})_{35},(\mathrm{dT})_{60},(\mathrm{dT})_{76}$ or $(\mathrm{dT})_{120}$ or ssDNA of phage M13 (1.5 pmol) was incubated for 20 min at $25^{\circ} \mathrm{C}$ with 10,100 or 200 pmol of TmaSSB or TneSSB in $10 \mu \mathrm{l}$ of binding buffer $(20 \mathrm{mM}$ Tris- $\mathrm{HCl} \mathrm{pH}$ $7.5,1 \mathrm{mM}$ EDTA) containing $2 \mathrm{mM}$ or $100 \mathrm{mM} \mathrm{NaCl}$. Next, the reaction products were loaded onto $2 \%$ agarose gels without ethidium bromide and separated by electrophoresis in TAE buffer $(40 \mathrm{mM}$ Tris acetate $\mathrm{pH}$ 7.5, $1 \mathrm{mM}$ EDTA). The bands corresponding to the unbound ssDNA, and the various SSB-ssDNA complexes following ethidium bromide staining were visualized by UV light and photographed.

\section{Fluorescence titration}

Fluorescence was measured with a Perkin-Elmer LS-5B luminescence spectrometer as described earlier [28]. For the binding reaction, $2 \mathrm{ml}$ binding buffer $(20 \mathrm{mM}$ Tris$\mathrm{HCl} \mathrm{pH} \mathrm{7.5,} 1 \mathrm{mM}$ EDTA) containing 2 or $100 \mathrm{mM}$ $\mathrm{NaCl}$ was used. A constant amount of TmaSSB or TneSSB $(1 \mathrm{nM})$ protein was incubated in the buffer at $25^{\circ} \mathrm{C}$ with varying quantities of $(\mathrm{dT})_{76}$ oligonucleotide (from 0 to $0.8 \mathrm{nM}$ ). The excitation and emission wavelengths were 295 and $348 \mathrm{~nm}$, respectively. The binding curve was analyzed using the model as described by Schwarz and Watanabe [29] with $n$ as binding site size, $\omega \cdot K$ as cooperative binding affinity and fluorescence quench $Q_{\mathrm{f}}$ as parameters. Fluorescence quench is defined as $1-\mathrm{F}_{\text {bound }} / \mathrm{F}_{\text {free}}$, where $\mathrm{F}_{\text {free }}$ and $\mathrm{F}_{\text {bound }}$ denote the fluorescence intensities measured for free and nucleic acid bound protein, respectively

\section{Thermostability}

To determine the thermostability of the TmaSSB and TneSSB proteins, both an indirect and a direct (differential scanning calorimetry, DSC) method was used.

In the indirect method, a fixed quantity $(10 \mathrm{pmol})$ of a 5 end fluorescein-labeled oligonucleotide $(\mathrm{dT})_{35}$ was added to 10 pmol of TmaSSB, TneSSB or TaqSSB (control sample) preincubated at $85^{\circ} \mathrm{C}, 90^{\circ} \mathrm{C}, 95^{\circ} \mathrm{C}$ and $100{ }^{\circ} \mathrm{C}$ for $0,1,3,5$, $10,15,30$, and $60 \mathrm{~min}$ in $10 \mu \mathrm{l}$ binding buffer containing $100 \mathrm{mM} \mathrm{NaCl}$. In further experiments with the TmaSSB and TneSSB proteins, the incubation times at $100^{\circ} \mathrm{C}$ were increased to $2,4,8,10,11$ and $12 \mathrm{~h}$. After $20 \mathrm{~min}$ incubation at $25{ }^{\circ} \mathrm{C}$, the protein-DNA complexes were separated from free DNA by electrophoresis on a $2 \%$ agarose gel, and $50 \%$ quantities of protein- $(\mathrm{dT})_{35}$ complex were evaluated by densitometric analysis using the VersaDoc imaging system and the QuantityOne software (BioRad, USA).

Microcalorimetric measurements were performed using a NanoDSC microcalorimeter (Calorimetry Science Corporation, USA). Samples containing $1.5 \mathrm{mg} /$ $\mathrm{ml} \mathrm{SSB}$ in $50 \mathrm{mM}$ potassium phosphate buffer $\mathrm{pH} 7.5$ and $0.1 \mathrm{M} \mathrm{NaCl}$ were analyzed. The calorimetric scans were carried out between 20 and $130^{\circ} \mathrm{C}$ with a scan rate of $1^{\circ} \mathrm{C} / \mathrm{min}$ (Figure 6 ). The reversibility of the transition was checked by cooling and reheating the same sample with the scan rate of $1^{\circ} \mathrm{C} / \mathrm{min}$. Results from the DSC measurements were analyzed with the NanoAnalyze Software V 1.1 (TA Instruments, USA).

\section{Nucleotide sequence accession number}

The nucleotide sequences of the $s s b$ genes of $T$. maritima and T. neapolitana are available in the GenBank database under the accession numbers AAD35689 [20] and GU125728, respectively.

\section{List of abbreviations used}

dsDNA: Double-stranded DNA; OB fold: Oligonucleotide/oligosaccharidebinding fold; RPA: Replication protein A; SSB: Single-stranded-DNA-binding; ssDNA: Single-stranded DNA.

\section{Acknowledgements}

This work was supported by the Gdańsk University of Technology. We thank the Laboratory of Intermolecular Interaction of Biomacromolecules at the Centre of Excellence ChemBioFarm for allowing access to the NanoDSC microcalorimeter used in this work

\section{Author details}

${ }^{1}$ Gdańsk University of Technology, Department of Microbiology, ul. Narutowicza 11/12, 80-233 Gdańsk, Poland. ${ }^{2}$ Gdańsk University of Technology, Department of Pharmaceutical Technology and Biochemistry, ul. Narutowicza 11/12, 80-233 Gdańsk, Poland.

\section{Authors' contributions}

MO conceived of the study, carried out the molecular genetic studies, participated in the design of the study and drafted the manuscript. AG, MN and MM carried out the molecular genetic studies. MW performed homology modeling of TmaSSB and ECOSSB. JK participated in design of study and drafted the manuscript. All authors read and approved the final manuscript. 
Received: 9 June 2010 Accepted: 15 October 2010

Published: 15 October 2010

\section{References}

1. Greipel J, Urbanke C, Maass G: The single-stranded DNA binding protein of Escherichia coli. Physicochemical properties and biological functions. In Protein-Nucleic Acid Interaction. Edited by: Saenger W, Heinemann U. London: Macmillan; 1989:61-86.

2. Alani E, Thresher R, Griffith JD, Kolodner RD: Characterization of DNAbinding and strand-exchange stimulation properties of $y$-RPA, a yeast single-strand-DNA-binding protein. J Mol Biol 1992, 227:54-71.

3. Lohman TM, Overman LB: Two binding modes in Escherichia coli single strand binding protein-single stranded DNA complexes. Modulation by $\mathrm{NaCl}$ concentration. J Biol Chem 1985, 260:3594-3603.

4. Meyer RR, Laine PS: The single-stranded DNA-binding protein of Escherichia coli. Micobiol Rev 1990, 54:342-380.

5. Murzin AG: OB (oligonucleotide/oligosaccharide binding)-fold: common structural and functional solution for non-homologous sequences. EMBO J 1993, 2:861-867.

6. Dąbrowski S, Olszewski M, Piątek R, Brillowska-Dąbrowska A, Konopa G, Kur J: Identification and characterization of single-stranded-DNA-binding proteins from Thermus thermophilus and Thermus aquaticus - new arrangement of binding domains. Microbiology 2002, 148:3307-3315.

7. Bernstein DA, Eggington JM, Killoran MP, Misic AM, Cox MM, Keck JL: Crystal structure of the Deinococcus radiodurans single-stranded DNAbinding protein suggests a mechanism for coping with DNA damage. Proc Natl Acad Sci USA 2004, 101:8575-8580.

8. Eggington JM, Haruta N, Wood EA, Cox MM: The single-stranded DNAbinding protein of Deinococcus radiodurans. BMC Microbiol 2004, 4:2

9. Kur J, Olszewski M, Długołącka A, Filipkowski P: Single-stranded DNAbinding proteins (SSBs) - sources and applications in molecular biology. Acta Biochim Pol 2005, 52:569-574.

10. Witte G, Urbanke C, Curth U: Single-stranded DNA-binding protein of Deinococcus radiodurans: a biophysical characterization. Nucleic Acids Res 2005, 21:1662-1670.

11. Olszewski M, Mickiewicz M, Kur J: Two highly thermostable paralogous single-stranded DNA-binding proteins from Thermoanaerobacter tengcongensis. Arch Microbiol 2008, 190:79-87.

12. Dąbrowski S, Olszewski M, Piątek R, Kur J: Novel thermostable ssDNAbinding proteins from Thermus thermophilus and T. aquaticus expression and purification. Protein Expr Purif 2002, 26:131-138.

13. Filipkowski P, Duraj-Thatte A, Kur J: Novel thermostable single-stranded DNA-binding protein (SSB) from Deinococcus geothermalis. Arch Microbiol 2006, 186:129-137.

14. Filipkowski P, Duraj-Thatte A, Kur J: Identification, cloning, expression, and characterization of a highly thermostable single-stranded DNA-binding protein (SSB) from Deinococcus murrayi. Protein Expr Purif 2007, 53:201-208.

15. Filipkowski P, Koziatek M, Kur J: A highly thermostable, homodimeric single-stranded DNA-binding protein from Deinococcus radiopugnans. Extremophiles 2006, 10:607-614.

16. Filipkowski P, Kur J: Identification and properties of the Deinococcus grandis and Deinococcus proteolyticus single-stranded DNA binding proteins (SSB). Acta Biochim Pol 2007, 54:79-87.

17. Wadsworth RI, White MF: Identification and properties of crenarchaeal single-stranded DNA binding protein from Sulfolobus solfataricus. Nucleic Acid Res 2001, 29:914-920.

18. Belkin $\mathrm{S}$, Wirsen $\mathrm{CO}$, Jannasch HW: A new sulfur-reducing, extremely thermophilic eubacterium from a submarine thermal vent. Appl Environ Microbiol 1986, 51:1180-1185.

19. Huber RJ, Langworthy TA, Konig H, Thomm M, Woese CR, Sleytr UB, Stetter KO: Thermotoga maritima sp. nov. represents a new genus of unique extremely thermophilic eubacteria growing up to $90^{\circ} \mathrm{C}$. Arch Microbiol 1986, 144:324-333.

20. Nelson KE, Clayton RA, Gill SR, Gwinn ML, Dodson RJ, Haft DH, Hickey EK, Peterson JD, Nelson WC, Ketchum KA, McDonald L, Utterback TR, Malek JA, Linher KD, Garrett MM, Stewart AM, Cotton MD, Pratt MS, Phillips CA, Richardson D, Heidelberg J, Sutton GG, Fleischmann RD, Eisen JA, White O, Salzberg SL, Smith HO, Venter JC, Fraser CM: Evidence for lateral gene transfer between Archaea and bacteria from genome sequence of Thermotoga maritime. Nature 1999, 399:323-329.
21. Lindner C, Nijland R, van Hartskamp M, Bron S, Hamoen LW, Kuipers OP: Differential expression of two paralogous genes of Bacillus subtilis enconding single-stranded DNA binding protein. J Bacteriol 2004, 186:1097-1105.

22. Madden TL, Tatusov RL, Zhang J: Applications of network BLAST server. Methods Enzymol 1996, 266:131-141.

23. Raghunathan S, Kozlov AG, Lohman TM, Waksman G: Structure of the DNA binding domain of E. coli SSB bound to ssDNA. Nat Struct Biol 2000, 7:648-652.

24. DiDonato M, Krishna SS, Schwarzenbacher R, McMullan D, Jaroszewski L, Miller MD, Abdubek P, Agarwalla S, Ambing E, Axelrod H, Biorac T, Chiu HJ, Deacon AM, Elsliger MA, Feuerhelm J, Godzik A, Grittini C, Grzechnik SK, Hale J, Hampton E, Haugen J, Hornsby M, Klock HE, Knuth MW, Koesema E, Kreusch A, Kuhn P, Lesley SA, Moy K, Nigoghossian E, Okach L, Paulsen J, Quijano K, Reyes R, Rife C, Spraggon G, Stevens RC, van den Bedem H, Velasquez J, White A, Wolf G, Xu Q, Hodgson KO, Wooley J, Wilson IA: Crystal structure of a single-stranded DNA-binding protein (TM0604) from Thermotoga maritima at 2.60 A resolution. Proteins 2006, 63:256-260.

25. Huson DH, Richter DC, Rausch C, Dezulian T, Franz M, Rupp R: Dendroscope: An interactive viewer for large phylogenetic trees. BMC Bioinformatics 2007, 8:460.

26. Atrazhev A, Zhang S, Grosse F: Single-stranded DNA binding protein from calf thymus. Purification, properties, and stimulation of the homologous DNA-polymerase-a-primase complex. Eur J Biochem 1992, 210:855-865.

27. Rudolf $R, B$ Böhm G, Lilie $H$, Jaenicke R: Folding proteins. In Protein Function: a Practical Approach.Edited by: Creighton TE. Oxford: IRL Press; 1996.

28. Curth U, Greipel J, Urbanke C, Maass G: Multiple binding modes of the single-stranded DNA binding protein from Escherichia coli as detected by tryptophan fluorescence and site-directed mutagenesis. Biochemistry 1993, 32:2585-2591.

29. Schwarz G, Watanabe F: Thermodynamics and kinetics of cooperative protein-nucleic acid binding. I. General aspects of analysis of data. J Mol Biol 1983, 163:467-484.

30. Raghunathan S, Ricard CS, Lohman TM, Waksman G: Crystal structure of the homo-tetrameric DNA binding domain of Escherichia coli singlestranded DNA-binding protein determined by multiwavelength $x$-ray diffraction on the selenomethionyl protein at 2.9-A resolution. Proc Natl Acad Sci USA 1997, 94:6652-6657.

31. Sali A, Blundell TL: Comparative protein modelling by satisfaction of spatial restraints. J Mol Biol 1993, 234:779-815.

32. Li WF, Zhou XX, Lu P: Structural features of thermozymes. Biotechnol Adv 2005, 23:271-281.

33. Vieille C, Burdette DS, Zeikus JG: Thermozymes. Biotechnol Annu Rev 1996 2:1-83.

34. Ladenstein R, Antranikian G: Proteins from hyperthermophiles: stability and enzymatic catalysis close to the boiling point of water. Adv Biochem Eng Biotechnol 1998, 61:37-85.

35. Russell RJM, Ferguson JM, Hough DW, Danson MJ, Taylor GL: The crystal structure of citrate synthase from the hyperthermophilic Archaeon Pyrococcus furiosus at 19 angstrom resolution. Biochemist 1997, 36:9983-94.

36. Lawrence MC, Colman PM: Shape complementarity at protein/protein interfaces. J Mol Biol 1993, 234:946-950

37. Humphrey W, Dalke A, Schulten K: VMD - Visual Molecular Dynamics. J Molec Graphics 1996, 14:33-38.

38. Rother K, Preissner R, Goede A, Froemmel C: Inhomogeneous molecular density: reference packing densities and distribution of cavities within proteins. Bioinformatics 2003, 19:2112-2121.

doi:10.1186/1471-2180-10-260

Cite this article as: Olszewski et al.: Characterization of exceptionally thermostable single-stranded DNA-binding proteins from Thermotoga maritima and Thermotoga neapolitana. BMC Microbiology 2010 10:260. 